\title{
Wait a Minute: The Efficacy of Discounting versus Non-Pecuniary Payment Steering
}

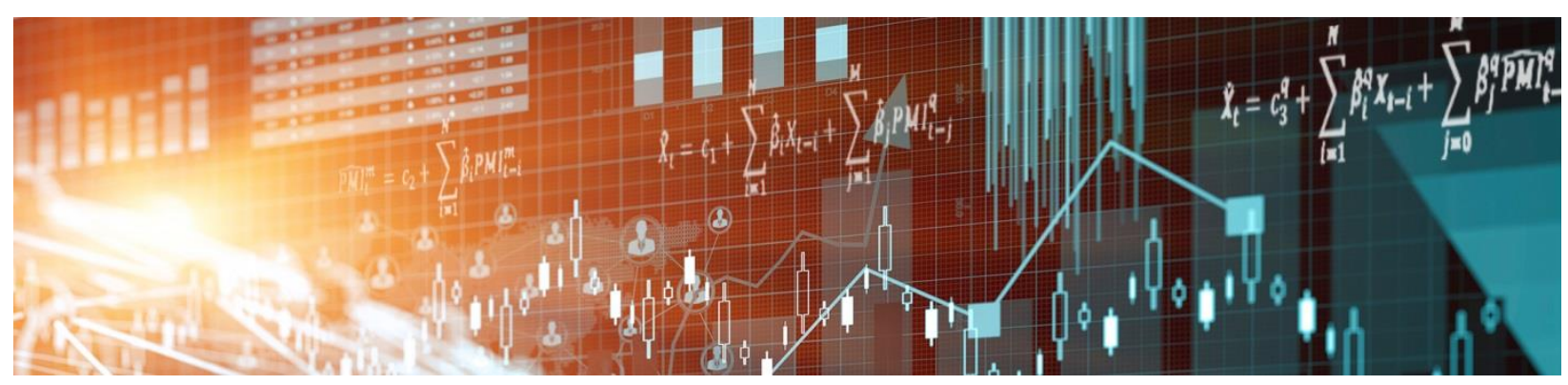

by Angelika Welte 
Bank of Canada Staff Working Paper 2016-8

February 2016

\section{Wait a Minute: The Efficacy of Discounting versus Non-Pecuniary Payment Steering}

by

\section{Angelika Welte}

Currency Department

Bank of Canada

Ottawa, Ontario, Canada K1A 0G9

awelte@bankofcanada.ca 


\section{Acknowledgements}

The author is indebted to Victor Aguirregabiria, Tamas Briglevics, Ben Fung, Laura Grigolon, Kim P. Huynh, Kostas Metaxoglou, Scott Schuh, Marcel Voia and Yanling Wang for their comments and support. The author acknowledges discussion with Mati Dubrovinsky during early stages of the discounting model. 


\begin{abstract}
Merchants who accept credit cards face payment processing fees. In most countries, the no-surcharge rule prohibits them from using surcharges to pass these fees on to customers. However, merchants are allowed to steer consumers toward less costly payment methods by offering discounts or using non-pecuniary incentives such as convenience and speed. Drawing upon micro data from a survey of Canadian households, I estimate a discrete choice model of consumers' payment methods to establish merchant costs for both of these strategies. I find that, while discounts are unprofitable because they subsidize a large portion of consumers who are already using cash and debit cards, non-pecuniary steering can be an effective strategy for transactions above \$25.
\end{abstract}

JEL classification: D12, E58, G28

Bank classification: Bank notes; Market structure and pricing; Payment clearing and settlement systems

\title{
Résumé
}

Les commerçants qui acceptent les cartes de crédit doivent supporter des frais pour le traitement des paiements. Dans la plupart des pays, une règle de non-imposition de frais supplémentaires leur interdit d'imputer ces frais de transaction aux consommateurs. Toutefois, les commerçants sont autorisés à diriger les consommateurs vers des modes de paiement moins coûteux en offrant des rabais, ou en recourant à des mesures incitatives non pécuniaires, notamment en faisant valoir la commodité et la rapidité de ces autres moyens de paiement. À partir de microdonnées tirées d'une enquête menée auprès des ménages canadiens, un modèle de choix discrets des modes de paiement est estimé afin d'établir les coûts respectifs de ces deux stratégies pour le commerçant. Il ressort des résultats que les rabais ne sont pas rentables, parce qu'ils servent à subventionner une part importante des consommateurs qui utilisent déjà l'argent comptant ou la carte de débit, mais que les mesures incitatives non pécuniaires peuvent constituer une stratégie efficace dans le cas des transactions supérieures à $25 \$$.

Classification JEL : D12, E58, G28

Classification de la Banque : Billets de banque; Structure de marché et fixation des prix; Systèmes de compensation et de règlement des paiements 


\section{Non-Technical Summary}

Canadian merchants who accept credit cards face payment processing fees, but are prohibited from using surcharges to pass these fees on to customers. However, merchants are allowed to steer consumers toward less costly payment methods by discounts or non-pecuniary incentives such as convenience and speed. Drawing upon micro data from a survey of Canadian households, the 2009 Methods-of-Payment Survey, I estimate a model of consumer payment choice and merchant costs for both of these strategies. While discounts turn out to be unprofitable because they subsidize a large portion of consumers who are already using cash and debit cards, non-pecuniary steering can be an effective strategy for transactions above $\$ 25$.

\section{Data}

Consumer data come from the payment diary of the 2009 Methods-of-Payment Survey. Survey respondents kept a diary and recorded their payment transactions over a 3-day period. Three key features of the data are needed for this paper: (i) transaction records, including the payment method, transaction amount, type of good, size of the store and a list of the payment methods accepted at the store; (ii) respondents' perceptions of payment methods, in terms of ease-of-use, record keeping, cost and other relevant attributes; (iii) the level of rewards earned by the respondents' credit cards.

The cost for the merchants is taken from a 2006 survey of Canadian retailers. The cost functions depend on the method of payment and the transaction amount, and are the same across all merchants.

\section{Future Research}

Future research should consider that merchants of different size and operating in different retail sectors may face different cost functions. Another interesting extension would be to incorporate the competitive advantages gained by accepting credit cards or offering discounts. 


\section{Introduction}

Merchants who accept credit cards face payment processing fees. However, although credit cards are the costliest payment method to accept (Arango and Taylor (2008)), in most countries the no-surcharge rule prohibits merchants from surcharging consumers for credit card payments. At the same time, consumers are offered pecuniary incentives to use credit cards, such as reward schemes and easy access to credit, or non-pecuniary incentives such as secure, fast and convenient payments. To merchants, the no-surcharge rule interrupts the price signal by which they convey to consumers which payment method is the least costly (Wright (2004)). On the other hand, while signalling through discounts for less costly payment methods is allowed and has been suggested as an alternative to surcharges, Briglevics and Shy (2014) find that such discounts are rarely observed. Merchants may accept card payments for competitive reasons because they can increase prices or attract more demand and the net effect on their profit is positive, a strategy called merchant internalization (Ding (2014)). However, merchant internalization is beyond the scope of this paper. Instead, using micro data from the Bank of Canada's 2009 Methods-of-Payment (MOP) Survey (see Arango and Welte (2012) for a full survey report), this paper discusses two types of steering by merchants: non-pecuniary steering by convenience and pecuniary steering by discounts. The main contributions to the existing literature on payment choice are: first, to extend the model of Briglevics and Shy (2014) by an estimated consumer-response curve to discounts, and, second, to study the efficacy of non-pecuniary steering. Discounts are unprofitable because they effectively subsidize a large portion of consumers who are already using cash and debit cards.

Consumer choice is modelled as a multivariate logit model (Section 2). The discounting simulation is summarized in Section 3 and non-pecuniary steering in Section 4. Section 5 concludes. 


\section{Merchant minimization problem}

Merchants strive to minimize the average cost of accepting payments, given consumers' payment preferences. Consider percentage discounts for cash and debit cards, given by vectors $d=\left(d_{\text {cash }}, d_{\text {debit }}\right) \in[0,1] \times[0,1]$. For each transaction, the probability that the consumer chooses mop from the available payment methods is a function $\operatorname{pr}_{\text {mop }}(T, d)$ of $T$ and $d$, where $T$ is a vector of transaction characteristic, consumer demographics and the consumers' incentives to use mop.

To numerically solve the merchant minimization problem for the optimal discount, these choice probabilities, $p r_{m o p}(T, d)$, are estimated using a multivariate logit model, based on Arango et al. (2015) and Wakamori and Welte (2012). The MOP survey provides the demographic profile of a representative sample of over 3,000 consumers, specifically their payment preferences and habits. Since the respondents provided detailed transaction records in a 3-day diary, the choice of payment method can be modelled on the transaction level. ${ }^{1}$

Pecuniary incentives enter the latent utility of the choice model as credit card rewards. As in Arango et al. (2015), credit card rewards are the product of the transaction value (TV) and the percentage of rewards on consumer $i$ 's credit card $d_{\text {credit }, i}$, that is $d_{\text {credit }, i} \cdot T V$. Rewards for other payment methods equal zero. Non-pecuniary incentives enter as the consumer's perceptions of a payment method's ease-of-use and security. Choice sets take into account perceived acceptance at the point-of-sale and ownership of payment cards; cash, however, is always in the choice set.

The model's coefficients are summarized in Table 1 and align with the results in Arango et al. (2015) and Wakamori and Welte (2012). Credit card rewards and ease-of-use significantly influence consumers' choice of payment method. Credit limits and carrying a balance ("revolving") control for the use of credit cards as access to credit. Consumers who hold more cash are less likely to use debit and credit cards, capturing the cash-in-advance constraint.

\footnotetext{
${ }^{1}$ The estimation uses about 50 per cent of the raw data. A description of the cleaning procedures is available upon request.
} 


\section{Steering with discounts is not profitable}

From the logit model, the consumer's utilities $U_{m o p}(T)$ are known when no discounts are offered. Every dollar in credit card rewards adds 0.15 units to credit card utility (Table 1). Lacking data on discounts, assume that consumers derive the same utility from a $\$ 1$ discount as from $\$ 1$ earned in credit card rewards. The utilities under discounting are simulated as

$$
\begin{aligned}
U_{\text {cash }}(T, d) & =U_{\text {cash }}(T)+0.15 \cdot d_{\text {cash }} \cdot T V, \\
U_{\text {debit }}(T, d) & =U_{\text {debit }}(T)+0.15 \cdot d_{\text {debit }} \cdot T V, \\
U_{\text {credit }}(T, d) & =U_{\text {credit }}(T) .
\end{aligned}
$$

The expected consumer benefit for the transaction is

$$
E(U)=E\left(\max \left\{U_{\text {cash }}(T, d), U_{\text {debit }}(T, d), U_{\text {credit }}(T, d)\right\}\right) .
$$

Since the consumer chooses the payment method with the highest utility, $p_{\text {credit }}(T, d)<$ $p_{\text {credit }}(T, 0)$ if $d_{\text {cash }}>0$ or $d_{\text {debit }}>0$. The merchants' transaction costs are given by

$$
\begin{aligned}
V_{\text {cash }}(T V, d) & =0.075+0.0047 \cdot T V+d_{\text {cash }} \cdot T V, \\
V_{\text {debit }}(T V, d) & =0.19+d_{\text {debit }} \cdot T V, \\
V_{\text {credit }}(T V, d) & =0.08+0.02 \cdot T V,
\end{aligned}
$$

where the costs before discounting are adopted from Arango and Taylor (2008). Without discounts, credit cards are most expensive for merchants, while cash is cheapest below $\$ 25$ and debit cards are cheapest above $\$ 25$. The expected merchant cost is the sum of expected 
costs for all transactions:

$E(V)=\sum_{T}\left(p_{\text {cash }}(T, d) \cdot V_{\text {cash }}(T V, d)+p_{\text {debit }}(T, d) \cdot V_{\text {debit }}(T V, d)+p_{\text {credit }}(T, d) \cdot V_{\text {credit }}(T V, d)\right)$.

Merchants who offer a cash or debit discount give that discount to all customers who choose the discounted payment method. ${ }^{2}$ If discounts are profitable, they are compensated for those discounts because the credit card share is reduced. For a transaction $T$, a discount for cash or debit is clearly only profitable if $V_{\text {debit }}(T V, d)<V_{\text {credit }}(T V, d)$ and $V_{\text {cash }}(T V, d)<V_{\text {credit }}(T V, d)$, since credit cards are always the most expensive. However, the profitability of discounts declines if consumers already have strong preferences for cash or debit. The following simplified example, adapted from Briglevics and Shy (2014), illustrates this intuition. Assume that the merchant accepts only cash and credit cards and that the transaction amount is always $\$ 25$. The inequality $V_{\text {cash }}\left(\$ 25, d_{\text {cash }}\right)<V_{\text {credit }}(\$ 25)$ holds if and only if $d_{c a s h}<0.0125$. Say the merchant would like to offer a 1 per cent discount for cash transactions of $\$ 25$ and define $\delta=p_{\text {credit }}(\$ 25,0.01)-p_{\text {credit }}(\$ 25,0)$, the reduction in the credit card share when offered a discount. Let $p=p_{\text {cash }}(\$ 25,0)$, the share of cash users when the merchant offers no discounts. The expected savings would increase if cash were costless, hence an upper bound for the expected savings net of the additional cost of the discount is given by

$$
\begin{array}{ll} 
& \delta \cdot \$ 25 \cdot 0.02 \\
\text { net } \quad & \frac{(p+\delta) \cdot \$ 25 \cdot 0.01}{\$ 25 \cdot(\delta \cdot 0.02-(p+\delta) \cdot 0.01)}
\end{array}
$$

Some algebra shows that the last line is positive if and only if $p<\delta \leq 1-p$. In other words, the larger the initial cash share $p$, the more credit card users have to be steered. The condition on $\delta$ means that the cash share has to at least double for discounting to

\footnotetext{
${ }^{2}$ Merchants are often obliged to mark discounts clearly at the point of sale, e.g. per the Code of Conduct for the Credit and Debit Card Industry in Canada.
} 
be profitable, which is more difficult to achieve when the cash share is already large, and impossible if the cash share is equal to or greater than 0.5 .

In the data, cash and debit usage before discounting (52 per cent and 27 per cent) is high before discounting and the simulated reduction in credit card payments achieved through steering consumers toward cash or debit payments is not large enough to offset the additional cost. For example, a 2 per cent cash discount increases the cash share by 2 per cent and lowers debit and credit shares by about 1 per cent, respectively, while adding $\$ 0.07$ to the average transaction cost (up from $\$ 0.37$ without the discount). ${ }^{3}$

\section{Steering with speed and convenience may be effec- tive}

As an alternative to discounts or surcharges for credit cards, merchants can offer faster and more convenient processing of cash and debit cards. For example, merchants may slow down the processing of credit card payments or have cash-only checkouts. Since consumers value convenience in payment methods, both the credit card share and the merchant's cost should decrease in response to this non-pecuniary incentive. However, if credit card usage becomes too inconvenient, the merchant risks lower customer satisfaction. The data do not allow modelling of competition between merchants or cost as a function of customer satisfaction. Instead, the elasticities of consumer utility (satisfaction) and of merchant cost to ease-of-use can be compared, since non-pecuniary steering can be efficacious if the relative effect on merchant cost is larger than the relative effect on consumers.

Assume the perceived reduction $q$ in the ease-of-use of a credit card payment to be uniformly distributed between $\left[0, q_{\max }\right]$, where $q_{\max }$ corresponds to the perception that credit cards are extremely fast and easy, while cash and debit cards are extremely slow and difficult. Credit card utility is reduced by $-\beta_{q} q$, where $\beta_{q}=0.35$ is the coefficient on ease-of-use in

\footnotetext{
${ }^{3}$ Detailed results are available upon request.
} 
the credit card equation; thus, $E(U)$ in $(1)$ and $E(V)$ in (2) can be written as functions of $q$. Denote by $E L U\left(q_{0}\right)$ and $E L V\left(q_{0}\right)$ the elasticities of $E(U)$ (respectively of $E(V)$ ) to changes in $q$, evaluated at $q_{0}$. The average ratio of elasticity of consumer utility and elasticity of merchant cost to ease-of-use is given by

$$
E L V / E L U:=\int_{q_{0}} \frac{E L V\left(q_{0}\right)}{E L U\left(q_{0}\right)} d q_{0} .
$$

By this ratio, relative effects of a change in ease-of-use on consumers and merchants can be compared in a unit-free manner. Figure 1 plots $E L V / E L U$ for different payment values as well as for grocery stores and restaurants. Consumer utility is more elastic than merchant cost for low-value transactions up to about $\$ 25$, but less elastic at higher transaction values. The ratio is also greater for restaurants than for grocery stores. Since ease-of-use is often understood as speed of payment, this can be interpreted as a greater willingness to wait for the bill at a restaurant than for the receipt at a supermarket checkout.

\section{Conclusion}

This paper exploits micro data from the MOP diary, a survey of Canadian households, to determine whether merchants can steer consumers away from credit cards without using surcharges. The model of merchant cost in this paper is similar to that of Briglevics and Shy (2014), with the addition of a consumer-response curve to discounts and non-pecuniary steering. As in Briglevics and Shy (2014), percentage discounts are shown to be unprofitable. Offering no discounts is therefore optimal for merchants, explaining why discounts are rarely observed. The main intuition is, as in Briglevics and Shy (2014), that merchants lose money on discounts because they have to subsidize a large proportion of consumers who already prefer less costly payment methods. Furthermore, if discounted payment methods should remain of lower cost, then the window for percentage discounts is between 0 per cent and 2 per cent, and such discounts have only small effects on consumer behaviour. 
By contrast, non-pecuniary steering with convenience is efficacious for merchants for transactions above $\$ 25$ and potentially more efficacious at restaurants than at grocery stores. Future research should aim at confirming these findings for non-linear discounting schemes and in the presence of merchant heterogeneity in the cost function.

\section{References}

Arango, Carlos and Angelika Welte, "The Bank of Canada 2009 Methods-of-Payment Survey: Methodology and Key Results," Bank of Canada Discussion Paper, 2012, No. 2012-6.

- and Varya Taylor, "Merchants' Costs of Accepting Means of Payment: Is Cash the Least Costly?," Bank of Canada Review, 2008, 2008 (Winter), 15-23.

_ , Kim P Huynh, and Leonard Sabetti, "Consumer payment choice: Merchant acceptance versus pricing incentives," Journal of Banking and Finance, 2015, 55, 130-141.

Briglevics, Tamás and Oz Shy, "Why Don't Most Merchants Use Price Discounts to Steer Consumer Payment Choice?," Review of Industrial Organization, 2014, 44 (4), 367-392.

Ding, Rong, "Merchant internalization revisited," Economics Letters, 2014, 125 (3), 347 349.

Wakamori, Naoki and Angelika Welte, "Why Do Shoppers Use Cash? Evidence from Shopping Diary Data," Bank of Canada Working Paper, 2012, No. 2012-24.

Wright, Julian, "The Determinants of Optimal Interchange Fees in Payment Systems," The Journal of Industrial Economics, 2004, 52 (1), 1-26. 
TABle 1: Logit Model of Consumer Payment Choice

\begin{tabular}{lllll}
\hline & \multicolumn{2}{l}{ Credit Card } & \multicolumn{2}{l}{ Debit Card } \\
\hline & $\beta$ & s.e & $\beta$ & s.e \\
Constant & $-0.75^{* * *}$ & $(0.24)$ & $0.42^{* *}$ & $(0.19)$ \\
TV & & & & \\
Value $(\$)$ & $0.04^{* * *}$ & $(0.00)$ & $0.03^{* * *}$ & $(0.00)$ \\
Value $/ 1000$ & $-0.12^{* * *}$ & $(0.02)$ & $-0.09^{* * *}$ & $(0.01)$ \\
below 5 & $-1.50^{* * *}$ & $(0.25)$ & $-0.94^{* * *}$ & $(0.14)$ \\
below 10 & $-0.90^{* * *}$ & $(0.15)$ & $-0.78^{* * *}$ & $(0.12)$ \\
Rewards $d_{\text {credit }} \cdot T V$ & $0.23^{* * *}$ & $(0.1)$ & & \\
Point of sale & & & & \\
Size of store & & & & \\
1 cashier & Omitted & & Omitted & \\
2 to 5 cashiers & 0.11 & $(0.11)$ & 0.08 & $(0.09)$ \\
6 or more & $0.38^{* * *}$ & $(0.13)$ & $0.32^{* * *}$ & $(0.10)$ \\
Type of Good & & & & \\
Groceries & $-0.63^{* * *}$ & $(0.10)$ & $0.27^{* * *}$ & $(0.09)$ \\
Enter./Meal & $-0.66^{* * *}$ & $(0.13)$ & $-0.33^{* * *}$ & $(0.1)$ \\
Gasoline & 0.27 & $(0.21)$ & 0.04 & 0.19 \\
other & Omitted & & Omitted & \\
MOP & & & & \\
Cash hold./100 & $-0.34^{* * *}$ & $(0.04)$ & $-0.01^{* * *}$ & $(0.00)$ \\
Perceptions & & & & \\
Ease & $0.66^{* * *}$ & $(0.12)$ & $0.68^{* * *}$ & $(0.11)$ \\
Record keeping & $0.67^{* * *}$ & $(0.06)$ & $0.35^{* * *}$ & $(0.05)$ \\
Cost & $0.59^{* * *}$ & $(0.05)$ & $0.23^{* * *}$ & $(0.05)$ \\
Number of cards & $0.07^{* * *}$ & $(0.02)$ & $0.22^{* * *}$ & $(0.04)$ \\
Credit limit & $0.28^{* * *}$ & $(0.02)$ & & \\
Revolver & $-1.05^{* * *}$ & $(0.07)$ & & \\
\hline Log likelihood & -4428 & & & \\
Number of Parameters & 55 & & & \\
Number of Individuals & 1,999 & & & \\
Number of Transactions & 7,137 & & & \\
\hline \hline & & & & \\
\hline & & & & \\
\hline
\end{tabular}

Note: Table 1 omits the coefficients for the consumer demographics, which are available upon request. Standard errors are in parentheses and the 1, 5, and 10 per cent levels of significance are denoted by ${ }^{* * *}, * *$, and $*$, respectively. 
Figure 1: Elasticities of Merchant Cost and Consumer Utility

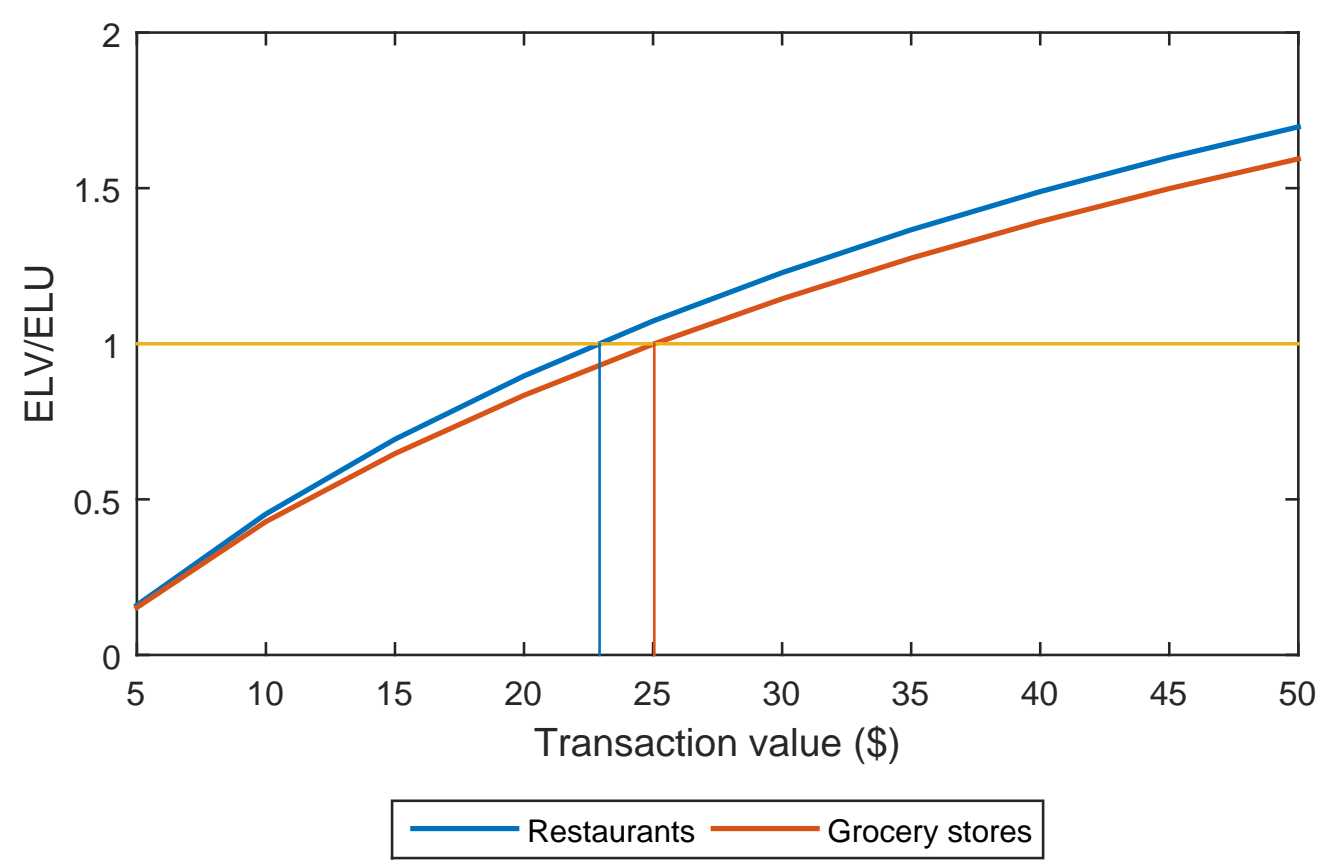

Note: The lines represent the average ratio of the elasticity of merchant cost and the elasticity of consumer utility at different transaction values when consumer convenience for using credit cards is reduced. 